\title{
The Validation of Ultrasound-Guided Lumbar Facet Nerve Blocks as Confirmed by Fluoroscopy
}

\author{
Heunguyn Jung, Seonghun Jeon, Sangho Ahn, Minwook Kim, Yongsoo Choi \\ Department of Orthopaedic Surgery, Kwangju Christian Hospital, Gwangju, Korea
}

Study Design: This is a prospective study.

Purpose: To develop a methodological approach for conducting ultrasound-guided lumbar facet nerve block by defining essential ultrasound-guided landmarks in order to assess the feasibility of this method.

Overview of Literature: The current role of ultrasound guidance for musculoskeletal intervention treatments has been reported upon in previous literature.

Methods: Ultrasound-guided facet nerve block was done in 95 segments for 50 patients with chronic back pain by facet arthropathy. After the surface landmarks of the spinous process and iliac crest line were confirmed, longitudinal facet views were obtained by a curved array transducer to identify the different spinal segments. The spinous process and facet joint with transverse process were delineated by transverse sonograms at each level and the target point for the block was defined as lying on the upper edge of the transverse process. The needle was inserted toward the target point. After a contrast injection, the placement of the needle and contrast was checked by fluoroscopy.

Results: Eighty-seven segments (91.6\%) could be guided successfully to the right facet nerve block by using ultrasound. After fluoroscopic control, 8 needles had to be corrected because of problems with other segments (3 cases) and lamina placements ( 5 cases). For the 42 patients who underwent successful block by ultrasound, however, the mean visual analogue score for back pain was improved from $6.2 \pm 0.9$ before the block to $4.0 \pm 1.0$ after the block $p=0.001$ )

Conclusions: Ultrasound-guided longitudinal facet view and the surface landmarks of the spinous process and iliac crest line seems to be a promising guidance technique for the lumbar facet nerve block technique.

Key Words: Lumbosacral region, Nerve block, Ultrasonography

\section{Introduction}

As the cause of chronic lower back pain, pain in the lumbar facet joint is relatively common, but nevertheless it is difficult to diagnose using only clinical examination or radiologic findings. This is further complicated by the fact that lumbar facet joints are often affected by degenerative alterations. A lumbar facet nerve block, i.e., selectively anesthetizing the medial branch of the dorsal ramus of the spinal nerve, is the accepted standard means of diagnosing facet joint-mediated pain today $[1,2]$. For a precise approach and to avoid complications, lumbar facet nerve block has been performed primarily by computed tomography (CT) or $\mathrm{C}$-arm fluoroscopy. The use of such equipment has disadvantages, in that both the patient and surgeon are exposed to radiation, and it can only be used in limited areas [3].

The current role of ultrasound guidance for musculoskeletal intervention treatments has been analyzed in past studies. Recently, interest in ultrasound-guided lumbar facet nerve block has been on the rise, and several studies have reported

Received Jul 31, 2011; Revised Oct 10, 2011; Accepted Oct 26, 2011

Corresponding author: Yongsoo Choi, MD

Department of Orthopaedic Surgery, Kwangju Christian Hospital,

37 Yangnim-ro, Nam-gu, Gwangju 503-715, Korea

Tel: +82-62-650-5064, Fax: +82-62-650-5066, E-mail: stemcellchoi@yahoo.co.kr

Copyright (C) 2012 by Korean Society of Spine Surgery

This is an Open Access article distributed under the terms of the Creative Commons Attribution Non-Commercial License (http://creativecommons.org/licenses/by-nc/3.0/) which permits unrestricted non-commercial use, distribution, and reproduction in any medium, provided the original work is properly cited. Asian Spine Journal • pISSN 1976-1902 eISSN 1976-7846 
relatively high success rates for this procedure [4-6]. However, ultrasound-guided identification of the correct segment for facet nerve block has not been fully described. Therefore, we conducted this study to develop a methodological approach for ultrasound-guided lumbar facet nerve block by defining the essential ultrasound views and sonographic landmarks necessary in the procedure, and evaluated the feasibility of this method.

\section{Materials and Methods}

The patients visited our hospital for chronic lower back pain and referred pain from February 2010 to June 2010. They were diagnosed as having lumbar facet syndrome based on their medical history, physical examination, radiography, magnetic resonance imaging (MRI), or CT. Fifty patients showed no satisfactory improvement of symptoms following medication, physical therapy and rehabilitation programs of more than 6 weeks. Ultrasound-guided facet nerve block was done in 95 segments for these fifty patients. Of these, 21 were male and 29 female. Their mean age was 64.5 years (range, 16 to 85 years). They were selected as suitable based on clinical symptoms and radiological facet pathology. Facet degeneration grades using MRI, as proposed by Grogan et al. [7], revealed 8 cases at grade 1, 42 cases at grade 2, 30 cases at grade 3 and 15 cases at grade 4 level. There was no significant relationship between facet degeneration grade and visual analogue scale (VAS) for back pain $(\mathrm{p}=0.347)$. In the procedure, patients were placed in a prone position and the lumbar lordotic curve was countervailed. Surface landmarks of the spinous process, il- iac crest line and needle target points were confirmed using anteroposterior lumbar radiograph after the spinous process and the posterior iliac crest line of patients were palpated (Fig. 1). To develop the necessary ultrasound view, the spinous process was first examined under high-resolution ultrasound with a 5-MHz curved transducer (LogiQ P5, GE, Milwaukee, USA). Longitudinal facet views were obtained by using a curved tranducer to identify different spinal segments (Fig. 2). The facet joint is better ultrasonic landmark for identification of anatomical level compared with the spinous process, and the accurate location was determined by counting the facet joint from the lumbosacral facet joint toward the cephalic direction. For the lower thoracic verte-

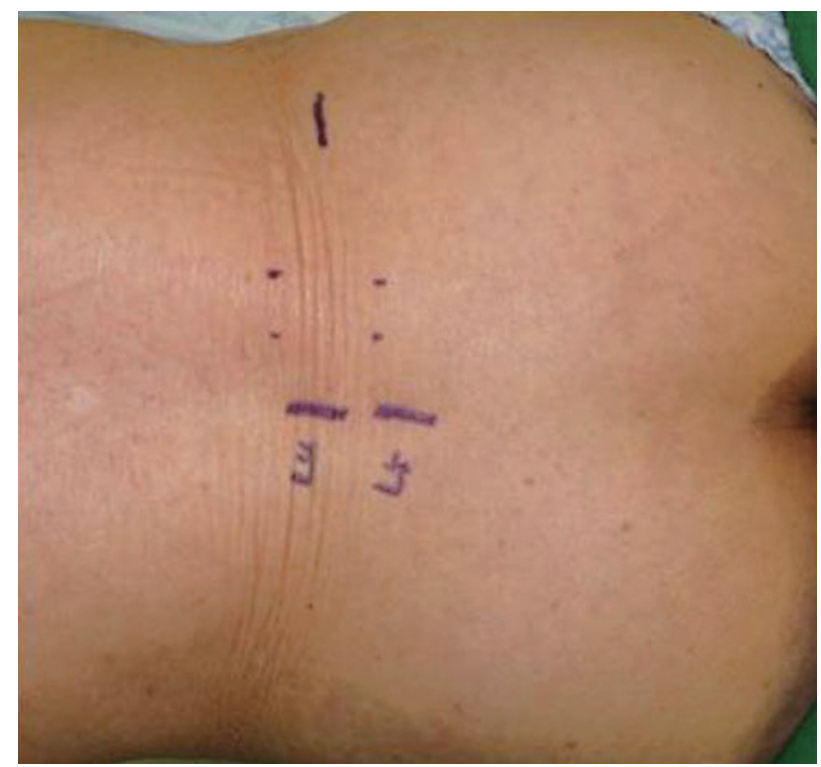

Fig. 1. Marking of L4-5 spinous process and iliac crest as surface anatomical landmarks.
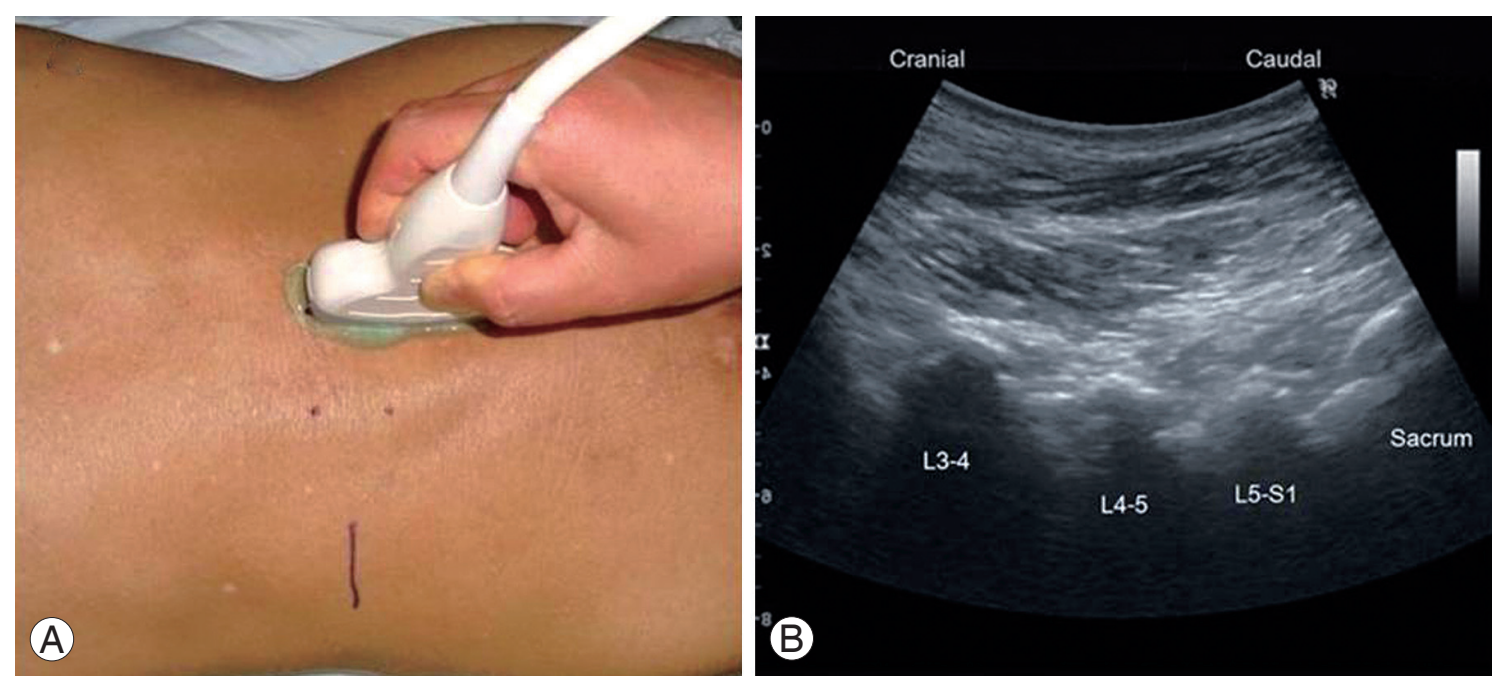

Fig. 2. Longitudinal facet views were obtained by curved tranducer to identify the different spinal segments (A), longitudial facet view by ultrasound showed L3-4, L4-5, and L5-S1 facet joints (B). 
brae or the upper lumbar spine vertebrae cases, an accurate location was assessed by using the 12th rib as a landmark. After finding the location of the desired vertebra, transverse axial images were obtained by rotating the probe by 90 degrees. The spinous process, facet joint and transverse process were delineated by transverse sonograms at each level and the target point for the block was defined as lying on the upper edge of the transverse process. A 21-G needle was inserted 15 degrees obliquely to the skin, $1 \mathrm{~cm}$ lateral to curved transducer and exactly in line with the transducer and the echo plane (Fig. 3). For validation of the facet nerve block, $0.5 \mathrm{ml}$ contrast media was injected. After a contrast injection, validation of the needle placement and facet nerve block was checked by the fluoroscopy. A successful block was the defined location of the needle at superiolateral edge of the lateral facet and contrast media distribution at posterior medial branch (Fig. 4A). A failed block occurred with an incorrect needle placement (see Fig. 4B for locations). A mixture of $1 \mathrm{ml} 2 \%$ lidocaine and $40 \mathrm{mg} / 1 \mathrm{ml}$ triamcinolone was used, which was injected after the needle was placed at the accurate site through C-arm fluoroscopy in failed block cases. Clinical results were evaluated 1 to 3 days after the procedure at outpatient follow-up observation, and the pain was evaluated using the VAS. For statistical analysis, the SPSS ver. 12.0 (SPSS Inc., Chicago, IL, USA) was used. We used a paired T-test to measure improvement of back

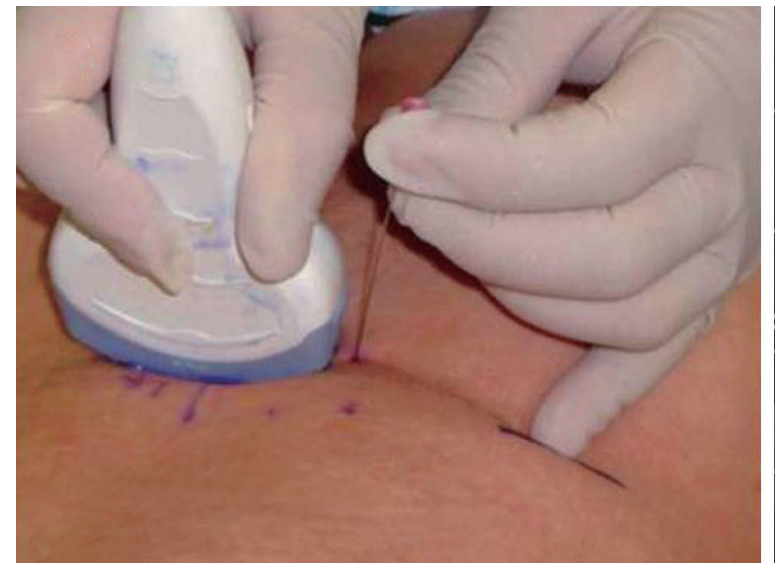

A

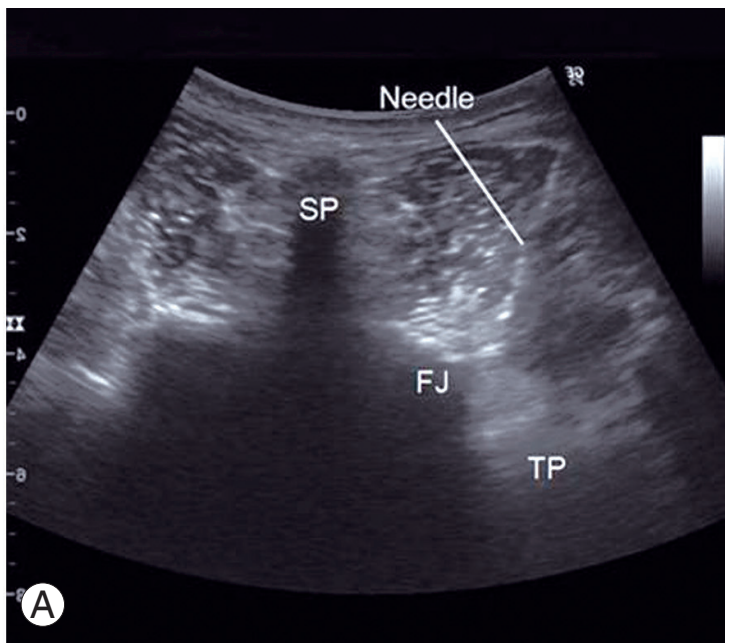

Fig. 3. Needle insertion between the superior articular process and on the upper edge of the transverse process. SP: Spinous process, FJ: Facet joint, TP: Transverse process.
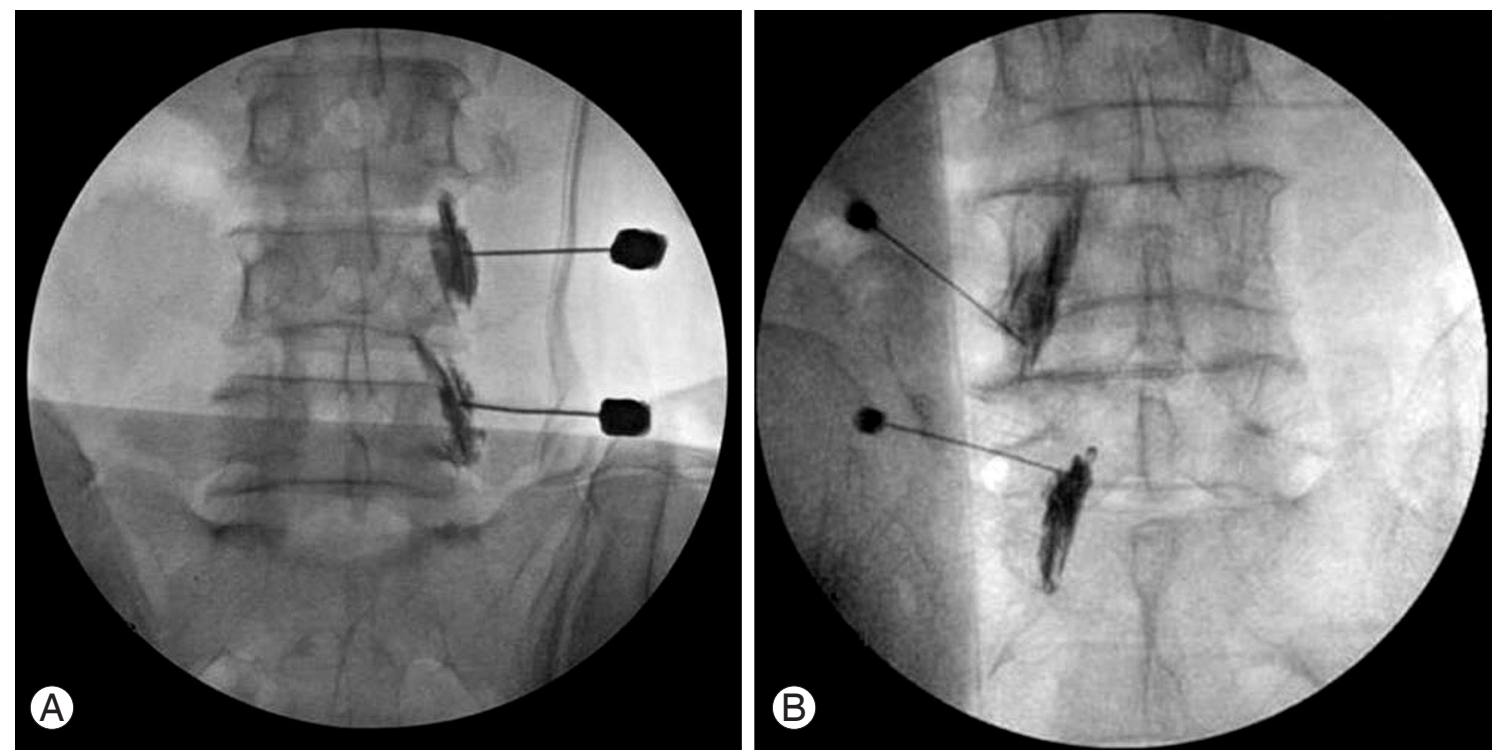

Fig. 4. The fluoroscopy revealed correct insertion of needle at the facet joint $(\mathbf{A})$ and the wrong insertion of needles (B). 
pain after facet nerve block in 42 patients who underwent successful block by ultrasound and also measured correlation analysis between the facet degeneration grade and VAS for back pain. The significance level was $p<0.05$.

\section{Results}

The lumbar facet nerve block was performed in one case at L1, one at L2, three at L3, 35 at L4, 48 at L5, and seven cases at S1. Among the total 95 segments, 87 segments $(91.6 \%)$ were guided successful facet nerve block by ultrasound. After fluoroscopic control, eight needles had to be corrected because of another segment in 3 cases and lamina placement in 5 cases. Concerning the failed locations, the L3-4 facet nerve accounted for two cases, the L4-5 facet nerve for five cases, and the L5-S1 facet nerve for one case. For 42 patients of successful block by ultrasound, the back pain was improved from a mean VAS $6.2 \pm 0.9$ before the block to a mean of VAS $4.0 \pm 1.0$ after the block $(p=0.001)$. There was no significant relationship found between the facet degeneration grade and VAS for improvement of back pain after a facet nerve block $(p=0.293)$.

\section{Discussion}

In 1933, the term facet joint syndrome was described as pain induced during twist or rotation of the lumbosacral area [8]. Nevertheless, radiological findings associated with the clinical diagnosis of facet joint syndrome are absent. Consequently, a block of the medial branch of the dorsal ramus of spinal nerve or a block of the facet joint itself using $\mathrm{CT}$ or $\mathrm{C}$-arm fluoroscopy has been performed for the diagnosis and treatment of the disease $[2,9,10]$. The use of ultrasonography has recently been increasing in the field of musculoskeletal disorders. It is an advantageous method for dynamically assessing sites on a real-time basis and in costeffective manner. Ultrasonography has emerged as an alternative method for lumbar facet nerve block using previous diagnostic equipment. However, the accuracy of facet nerve block using ultrasonography has not been proven, and thus its effectiveness is still controversial.

Ultrasonography usage for block procedures was first reported in 1978 by la Grange et al. [11], which attempted a brachial plexus nerve block using Doppler ultrasound. Afterward, the usefulness of the application of ultrasonography for peripheral nerve block or local anesthesia was reported in several studies $[3,12,13]$. In comparison with previous diagnostic devices, ultrasonography attracts attention because of several key advantages. First, there is no exposure to radiation involved. Although the radiation dose during the nerve block by CT or C-arm fluoroscopy is not large, physicians are exposed to many procedures, and thus when the total radiation dose for one year is examined, it becomes more significant, and the risk of irradiation hand damage rises for the surgeons involved [14]. Lee et al. [15] reported on a hand lesion that was damaged due to irradiation in this way. Second, additional equipment for protection against radiation is not required and the size of the equipment is small, so it can be moved easily and is thus able to be performed in outpatient clinics. Despite such advantages, the acoustic impedance of bone is high, and thus it does have limitations for imaging spinal structures. In addition, the reproducibility among doctors is low [16].

Greher et al. [5] reported a target point for facet nerve block as a ultrasonographic landmark, which was defined as lying on the upper edge of the transverse process and in the groove at the base of the superior articular process, where the medial branch traverses the upper edge of the transverse process. Ha et al. [6] performed facet joint block using the spinous process, the lamina, and the facet joint as landmarks. Previous studies have reported relatively high success rates for lumbar facet block using ultrasonography [4-6]. However, ultrasound-guided identification for facet nerve block has not been fully described. Ha et al. [6] reported improvement of symptoms after facet joint block, but they did not evaluated needle placement using radiological images in regard to the accuracy of lumbar facet nerve block.

To identify different spinal levels, most previous studies have applied spinous process as ultrasonic landmarks on posterior sagittal sonograms [4-6]. Yet it is not easy to identify different spinal levels using the spinous process as an ultrasonic landmark. Author's work suggests that ultrasoundguided longitudinal facet view obtained by curved tranducer seems to be a promising guidance technique for identifying different spinal segments. The facet joint is a better ultrasonic landmark for identification of anatomical level compared with the spinous process, and the accurate location could be determined by counting the facet joint from the lumbosacral facet joint toward cephalic direction. This study has reason, therefore, to compare accuracy between the ultrasonography and lumbar facet nerve block. Eighty-seven segments $(91.6 \%)$ could be guided successfully for facet nerve block by ultrasound.

The limitations of this study were as follows; firstly, there 
was $8.4 \%$ failure rate of the accuracy of lumbar facet nerve block using ultrasound guidance. To overcome this problem, we performed double blocks at the L5 medial branch and L4 medial branch to screen patients for L4-5 facet denervation. There is a dual innervation to each lumbar facet joint. That is, each facet is innervated by the medial branches of the posterior rami of the spinal nerves above and below the joint. Thus, the L4-5 facet is innervated by the L5 medial branch (coursing over the L5 transverse process) and the L4 medial branch (coursing over the L4 transverse process). Facet nerve block using fluoroscopic guidance was repeated if a patient had no improvement in terms of their back pain. A second limitation is that the medial branch of the facet joint was not examined neurologically to assess whether or not the location of the needles was accurate. Further investigation should consider this point, in order to clarify the location of needles more accurately for the medial branch of facet joint.

\section{Conclusions}

Ultrasound-guided longitudinal facet view and surface landmarks of the spinous process and iliac crest line seems to be a promising guidance technique for conducting lumbar facet nerve block. Ultrasound guidance seems to be both a more practical technique than other alternatives, and also mimimizes exposure to radiation in the lumbar facet nerve block process.

\section{REFERENCES}

1. Helbig T, Lee CK. The lumbar facet syndrome. Spine (Phila Pa 1976) 1988;13:61-4.

2. Saal JS. General principles of diagnostic testing as related to painful lumbar spine disorders: a critical appraisal of current diagnostic techniques. Spine (Phila Pa 1976) 2002;27:2538-45.

3. Peterson MK, Millar FA, Sheppard DG. Ultrasoundguided nerve blocks. Br J Anaesth 2002;88:621-4.

4. Greher M, Kirchmair L, Enna B, et al. Ultrasoundguided lumbar facet nerve block: accuracy of a new technique confirmed by computed tomography. Anesthesiology 2004;101:1195-200.

5. Greher M, Scharbert G, Kamolz LP, et al. Ultrasoundguided lumbar facet nerve block: a sonoanatomic study of a new methodologic approach. Anesthesiology 2004;100:1242-8.

6. Ha DH, Shim DM, Kim TK, Kim YM, Choi SS. Comparison of ultrasonography- and fluoroscopy-guided facet joint block in the lumbar spine. Asian Spine J 2010;4:15-22.

7. Grogan J, Nowicki BH, Schmidt TA, Haughton VM. Lumbar facet joint tropism does not accelerate degeneration of the facet joints. AJNR Am J Neuroradiol 1997;18:1325-9.

8. Ghormley RK. Low back pain with special reference to the articular facets with presentation of an operative procedure. JAMA 1933;101:1773-7.

9. Marks RC, Houston T, Thulbourne T. Facet joint injection and facet nerve block: a randomised comparison in 86 patients with chronic low back pain. Pain 1992;49:325-8.

10. Bogduk N, Marsland A. The cervical zygapophysial joints as a source of neck pain. Spine (Phila Pa 1976) 1988;13:610-7.

11. la Grange P, Foster PA, Pretorius LK. Application of the Doppler ultrasound bloodflow detector in supraclavicular brachial plexus block. Br J Anaesth 1978;50:965-7.

12. Kapral S, Krafft P, Eibenberger K, Fitzgerald R, Gosch $\mathrm{M}$, Weinstabl C. Ultrasound-guided supraclavicular approach for regional anesthesia of the brachial plexus. Anesth Analg 1994;78:507-13.

13. Marhofer P, Greher M, Kapral S. Ultrasound guidance in regional anaesthesia. Br J Anaesth 2005;94:7-17.

14. Watson-Jones R, Wilson JN. Fracture and joint injuries. 6th ed. Edinburgh: Churchill Livingstone; 1982.

15. Lee EW, Chun JM, Ahn BW, Park YW, Lee SY, Paik NC. A study of hand lesion exposed by radiation. J Korean Orthop Assoc 1991;26:841-6.

16. Hashimoto BE, Kramer DJ, Wiitala L. Applications of musculoskeletal sonography. J Clin Ultrasound 1999;27:293-318. 